\title{
Important Tools for Use by Pediatric Endocrinologists in the Assessment of Short Stature
}

\author{
(D) José I. Labarta1, (1) Michael B. Ranke2, (D) Mohamad Maghnie3,4, (D) David Martin5, (D) Laura Guazzarotti6, (D) Roland Pfäffle7, \\ (D) Ekaterina Koledova8, (1) Jan M. Wit9
}

1 University of Zaragoza, Children's Hospital Miguel Servet, Instituto de Investigación Sanitaria de Aragón, Unit of Endocrinology, Zaragoza, Spain 2University of Tübingen, Children's Hospital, Clinic of Pediatric Endocrinology, Tübingen, Germany

3 University of Genova, Department of Neuroscience, Rehabilitation, Ophthalmology, Genetics, Maternal and Child Health, Genova, Italy

4 IRCCS Instituto Giannina Gaslini, Department of Pediatrics, Genova, Italy

5 University of Witten/Herdecke and Tübingen University, Tübingen, Germany

GUniversity of Milan, Luigi Sacco Hospital, Clinic of Pediatric, Milan, Italy

7 University of Leipzig, Department of Pediatrics, Leipzig, Germany

8 Global Medical Affairs, Merck KGaA, Darmstadt, Germany

9 Leiden University Medical Centre, Department of Paediatrics, Leiden, Netherlands

\begin{abstract}
Assessment and management of children with growth failure has improved greatly over recent years. However, there remains a strong potential for further improvements by using novel digital techniques. A panel of experts discussed developments in digitalization of a number of important tools used by pediatric endocrinologists at the third $360^{\circ}$ European Meeting on Growth and Endocrine Disorders, funded by Merck KGaA, Germany, and this review is based on those discussions. It was reported that electronic monitoring and new algorithms have been devised that are providing more sensitive referral for short stature. In addition, computer programs have improved ways in which diagnoses are coded for use by various groups including healthcare providers and government health systems. Innovative cranial imaging techniques have been devised that are considered safer than using gadolinium contrast agents and are also more sensitive and accurate. Deep-learning neural networks are changing the way that bone age and bone health are assessed, which are more objective than standard methodologies. Models for prediction of growth response to growth hormone (GH) treatment are being improved by applying novel artificial intelligence methods that can identify non-linear and linear factors that relate to response, providing more accurate predictions. Determination and interpretation of insulin-like growth factor-1 (IGF-1) levels are becoming more standardized and consistent, for evaluation across different patient groups, and computer-learning models indicate that baseline IGF-1 standard deviation score is among the most important indicators of GH therapy response. While physicians involved in child growth and treatment of disorders resulting in growth failure need to be aware of, and keep abreast of, these latest developments, treatment decisions and management should continue to be based on clinical decisions. New digital technologies and advancements in the field should be aimed at improving clinical decisions, making greater standardization of assessment and facilitating patient-centered approaches.

Keywords: Short stature, height monitoring, bone age, cranial imaging, growth hormone treatment, prediction models
\end{abstract}

\section{Introduction}

One of the most important tools in monitoring the health of children is an assessment of how an individual child is growing relative to his/her peers. Linear growth monitoring of apparently healthy children can provide early indications of serious conditions (1), which may be identified through growth algorithms and the expertise of clinicians $(2,3)$. If a child is noted to be particularly short, the cause should be determined and referral to a pediatric endocrinologist is likely, where a diagnosis can often be assigned from factors such as body proportions and clinical and family history $(1,4)$. Although genetic abnormalities associated with short 
stature are continually being identified (5), a high percentage of cases remain idiopathic with no specified cause (6). While identified causes are often associated with defects in the growth hormone (GH)-insulin-like growth factor-1 (IGF-1) axis, a large proportion of cases do not involve GH or IGF-1 abnormalities, but may involve factors such as growth plate abnormalities $(3,5,7)$.

GH therapy to improve linear growth is approved for a number of conditions associated with growth failure in children, although this varies to some extent by $\mathrm{GH}$ formulation and country $(2,8,9,10,11)$. It is important for clinicians to identify ways of optimizing treatment; while starting $\mathrm{GH}$ treatment at a young age generally improves outcomes, for many indications, referral, diagnosis and $\mathrm{GH}$ initiation occur later than optimal $(2,8)$. Artificial intelligence and machine-learning are revolutionizing diagnostic tools in all areas of medicine, including child growth and development. It remains important for pediatric endocrinologists to continually assess the innovative techniques that are becoming available with regard to identifying the nature of growth failure in children and how to tailor the management of the condition.

The present report is based on a meeting held in Rome, Italy, funded by Merck KGaA, Darmstadt, Germany, which discussed important new tools being developed and used by pediatric endocrinologists. Accurately identifying which children should be defined as short, what is the cause of the short stature, problems relating to bone maturation and how a child with growth failure will respond to treatment can all be aided by digital technologies, leading to improved clinical decisions, greater standardization and patientcentered approaches.

\section{Growth Monitoring and Algorithms}

Among children referred for evaluation of short stature, the prevalence of pathological conditions is only approximately $5 \%$, with reported variation from $1.3 \%$ to $19.8 \%$ depending on the criteria considered $(12,13,14)$. Thus, the majority of referrals show no pathology and diagnostic work-up may be carried out unnecessarily $(3,15)$. Additionally, use of growth charts that are not population-specific can result in a large proportion of incorrect referrals for diagnostic work-up $(14,16,17)$. Using appropriate growth references is of paramount importance when assessing a child's height because of the impact on eligibility for therapy (17). Wide variations are reported in population height measurements and the choice of auxological criteria for referral for short stature $(12,13,14,18)$. Current protocols for growth monitoring frequently result in delayed diagnosis, and a consequent delay in the treatment of growth failure
$(19,20,21)$. Appropriate referrals will avoid unnecessary procedures and enable earlier diagnosis of the cause of growth failure and prompt initiation of therapy, thus improving outcomes and diminishing complications. Therefore, it is important that clinical practice should be optimized by standardization of growth monitoring, with validated, evidence-based protocols $(2,12,13)$.

There is currently a lack of consensus on criteria for definition of abnormal growth. Seven different algorithms have been published in the last 20 years, involving around eight auxological parameters to be evaluated (22). However, the level of validation is low for each of the algorithms, with widely varying sensitivities and specificities. While height standard deviation score (SDS) is used in all algorithms, there is no consensus concerning the cut-off. A study across 23 European countries found height SDS cut-off ranged from -1.64 to -2.67 SDS and growth deflection or height velocity cut-off ranged from -0.50 to -2.32 SDS (18). Distance to target height SDS is the second most frequently used parameter, but different formulae may be used for calculation and there may be inaccuracies in measurements of parental heights. Other parameters were based on dynamic growth indicators, such as height deflection and height velocity SDS.

Comparison of children using the Dutch, Finnish and UK guidelines showed variations in sensitivity and specificity (14). Distance to target height provided the best specificity, particularly using the Dutch guidelines, and combination with height SDS provided effective growth monitoring. However, sensitivity was much lower and, even using combinations of up to four criteria, at least $20 \%$ of children with pathological growth failure may not be identified by these auxological measurements. Adding growth deflection may improve sensitivity and in the pre-pubertal period recent growth deflection should be considered a "red flag", leading to referral to a specialist clinic (14). Strict application of guidelines and cut-offs may lead to excessive numbers of referrals and other parameters may need to be added (15). In children younger than three years height/ length measurements are often inaccurate; referral at this age should be based on extreme short stature or repeated measurements (23).

In children over three years of age, it was shown that electronic monitoring of growth, together with algorithms for assessment of auxology, could identify patients for referral for specialist care, and resulted in increased detection of pathological conditions associated with growth failure (24). In order for electronic health records to be clinically advantageous, good infrastructure and databases are required. With increasingly widespread collection, 
monitoring of height of individual children in relation to their peers should become automatic and improve accuracy of referrals. Despite this availability, few countries have currently adopted such use of electronic records and automated growth algorithms. Electronic monitoring of height and weight has been used to assess obesity in children in Canada $(25,26)$, but not linear growth and it was noted that better documentation by physicians was required. Currently, only the Scandinavian countries of Norway, Sweden and Finland have fully developed centralized systems for electronic recording and only Finland has implemented automated height growth analysis. However, it should be noted that factors such as being born small for gestational age, dysmorphic features or disproportionate short stature should also be assessed and appropriate algorithms be applied, emphasizing the importance at present of clinical judgment in making a diagnosis of the cause of growth failure.

\section{Categorization of Diagnoses}

When growth monitoring has indicated that a child has growth failure, the cause is determined from auxology, clinical history and biochemical assessments, and a diagnosis is ascribed. In order to analyze data on diagnoses from large populations it is necessary to transform the reported medical conditions into code numbers. These codes can then be used by health researchers, healthcare providers, government health programs, health insurance companies and others, for a variety of applications. A number of different systems have been designed to classify the diagnoses. The classification should allow inclusion of all patients, enable new etiologies and pathogenic aspects to be accommodated, define diagnoses accurately to prevent misclassification, follow one general principle, be easy to use and, optimally, serve the designed purpose (27). The International Classification of Diseases (ICD) was started in 1948 by the World Health Organization, and is now in version ten (http://apps.who.int/classifications/icd10/ browse/2010/en). Its aim is to delineate all major disease groups, but diagnoses are not well defined, with too many conditions included together. For example, the term "endocrine, nutritional and metabolic disease" includes thyroid disorders, diabetes and disorders that are not really related to endocrinology, such as malnutrition and obesity. Thus, the system does not prevent misclassification. Online Mendelian Inheritance in Man (OMIM; https://www.omim. org/) can only be used for genetic disorders. Also, unless phenotypic features or clinical history indicate what genes to examine, in most children with short stature there is no specific "candidate gene" for targeted analysis.
The European Society of Pediatric Endocrinology Classification of Pediatric Endocrine Diagnoses aimed to define all pediatric endocrine disorders and included multiple specific sections, such as the one for all conditions involving short stature (27). This has now been superceded by the online International Classification of Pediatric Endocrine Disorders (ICPED), which is a comprehensive system of pediatric conditions developed by an international group of experts and endorsed by all pediatric endocrinology societies $(28,29)$. The system incorporates the most recent versions of ICD-10 codes and OMIM numbering in order to be easily assimilated into hospital registries, and continues to be developed and added to. The online version is freely available (www.icped.org). While ICPED is used to a reasonable extent in the USA and Netherlands, its use in most other countries is limited. Worldwide standardization within pediatric endocrinology requires the use of ICPED for healthcare, economic and scientific purposes in order that electronic health records can be linked to diagnostic classification and coding systems.

\section{Cranial Imaging}

As part of the work-up for assigning a diagnosis for the cause of growth failure, cranial imaging is frequently included. However, the only consensus specifying which patients require cranial imaging were published in 2000 and have not been updated (30). They stated that patients with known or suspected intracranial tumors, optic nerve hypoplasia, septo-optic dysplasia or other structural or developmental anomalies should be assessed by magnetic resonance imaging (MRI) or computed tomography of the central nervous system. In patients with confirmed GH deficiency, pituitary height and/or volume, anatomy of the stalk and position of the posterior pituitary should be determined. The guidelines noted though that further normative data were required to improve the quality of assessment.

Standard MRI protocols include sagittal and/or coronal sections of 2-3 mm, with or without contrast medium, and pituitary height and/or volume, stalk anatomy and posterior pituitary position should be determined. Knowledge of the normal shape and volume of the pituitary is required to interpret the images and identify abnormalities $(31,32)$. It is also advised that a survey of the entire brain should be carried out, such as use of fluid attenuation inversion recovery or diffusion-weighted imaging $(32,33)$. MRI signals for the anterior pituitary and posterior pituitary are similar in the first few months of life, becoming different thereafter. The size/height of the anterior pituitary is $2.6-5 \mathrm{~mm}$ in the first postnatal 6 weeks, decreasing to $3 \mathrm{~mm}$ by two years and then increasing over time until puberty at 6-8 $\mathrm{mm}$; 
however, it should be noted that pituitary height at puberty is greater in females than in males. The position of the pituitary gland and connection with surrounding tissue are also important because abnormal development or migration of the pituitary may constitute some of the features of congenital hypopituitarism, confirming the requirement for assessing the surrounding brain from the imaging, along with the pituitary features.

Different imaging studies of patients with a diagnosis of hypopituitarism have shown normal pituitary in 0 to $86 \%$ of patients, hypoplastic anterior pituitary in 0 to $84 \%$, and ectopic posterior pituitary in $4 \%$ to $100 \%$ (34). However, ectopic posterior pituitary was observed more frequently when patients had multiple pituitary hormone deficiencies ( $>50 \%$ in 15 of 18 studies) rather than isolated $\mathrm{GH}$ deficiency ( $<50 \%$ in 13 of 18 studies) (34). Abnormal pituitary features may help to predict the development of pituitary hormone deficiencies and the most likely genes involved $(34,35)$. Thus, genetic studies can be better targeted by using MRI data together with associated phenotypic features, such as abnormalities of the brain, eyes and palate and additional central nervous system anomalies. Pituitary abnormalities also help in determining long-term status of GH deficiency; ectopic posterior pituitary or stalk abnormalities are associated with permanent GH deficiency whereas patients with isolated GH deficiency and a normal or small pituitary may have sufficient GH secretion at nearadult height and require re-testing $(36,37)$.

In order for such predictions of genetics and endocrine status to be accurate, the MRI techniques must be as sensitive as possible. To enhance the contrast of MRI scans, intravenous gadolinium-based agents have routinely been administered to patients for more than 20 years and were generally considered safe $(38,39,40)$. However, studies have indicated that gadolinium may be retained in the body, particularly in the brain when administered for pituitary imaging, so that after multiple administrations the contrast agents remained and deposits could be identified $(40,41)$. This raised questions as to whether such deposits have harmful effects and indicated that further research was needed. The studies prompted new evaluations by regulatory bodies and warnings have been added to the labels for gadolinium formulations $(42,43)$. This has led to new computer-aided techniques being developed, such as T2-DRIVE (driven equilibrium), whereby enhanced contrast can be attained without gadolinium administration (44). T2DRIVE actually appears to be more accurate than gadolinium contrast and enables extremely reliable evaluation of pituitary size and identification of abnormalities. Thus, the technique can greatly improve the diagnosis and knowledge of the pathogenesis of non-tumoral hypothalamic-pituitary disorders.

\section{Determination of Bone Age}

Another part of the work-up for evaluation of growth failure is an accurate assessment of bone age, which is important because bone age delay or advancement is a useful diagnostic clue, and is used to predict adult height $(45,46)$. Conventional assessments are known to be fraught with difficulties due to the many short-comings of the methods. There is no universally accepted method for manual assessment and great variability between individuals making the assessments. Healthcare personnel making the rating may differ in training, experience, motivation and alertness, and bias may be introduced if the rater knows the chronological age and clinical background of the patient. Variability can also occur due to ethnic differences, use of old/inappropriate reference data and lack of validation of methods; the original atlases were developed using data from particular ethnic and socio-economic groups (47).

It was recognized many years ago that computerized ratings could be better than conventional manual methods and a computer-assisted version of the Tanner-Whitehouse method was designed $(48,49)$. However, it was not fully automatic, cumbersome and only ever used by a small number of research centers. Advances in computer technology allowed better methods to be developed and the first reports of the fully-automated BoneXpert method were published just over 10 years ago $(50,51)$. The method uses X-radiographs of 15 bones in the wrist, hand and fingers, and originally did not use the carpals, which are considered to be less useful, although a new version does include carpals (52). The process interprets the shape, intensity and texture by principal component analysis and BoneXpert is currently the only medical device that has been certified for bone age determination.

Other systems have also recently been developed that use computer learning with deep convolutional neural networks, which do not require prior identification of features and calculations because these are part of the machine-learning process $(53,54,55)$. While not fully automated or validated, such techniques are improving the accuracy, shortening the time required and increasing the cost efficiency of bone age assessments $(56,57)$. A recent report provided evidence that an artificial intelligence, deep-learning, neural network method could estimate bone age with at least similar accuracy to expert radiologists and other existing automated models (58). These data for 12,611 hand radiographs, plus a further 1,425 validation data set, were used as part of a challenge issued by the Radiological Society of North America (RSNA) 
to create new machine-learning techniques in medical imaging to accurately determine bone age (59). The ten best entries were considered to out-perform the model used originally in the data-set study, and the Toronto-based 16Bit system (www.16bit.ai) achieved first place $(59,60)$. At present, there is only very limited understanding or control of deep-learning algorithms, making such techniques difficult to validate. However, eHealth technology is incorporating pediatric endocrinology into novel processes, enabling communication between technology experts and clinicians and ensuring assessments become more efficient and precise.

The BoneXpert system, which does not require deeplearning techniques, came fourth in the RSNA challenge, with less than $0.5 \%$ difference in performance from the $16 \mathrm{Bit}$ system. As BoneXpert is based on more traditional machine-learning techniques, it has some advantages over the novel deep-learning methods and is currently being used in over 150 clinics. It is validated for boys aged from 2.5 to 19 years and girls 2 to 18 years, although a new version extends the range to new-borns. BoneXpert can be used across multiple ethnicities and is consistent with all prevailing bone age scales $(52,61,62,63)$. Precision is $\leq 0.18$ years when comparing two concurrent X-radiographs, and accuracy is $\leq 0.72$ years relative to experienced manual raters. It provides visual feedback on delineation of each bone and automatically rejects an image if the rating is at risk of being incorrect, giving the potential to replace manual rating, although radiologists may still check the image to look for findings such as skeletal dysplasias. It has been validated with an adult height prediction model, with root mean square deviation of predicted from observed of $2.8 \mathrm{~cm}$ for boys and $3.1 \mathrm{~cm}$ for girls (63). The technique can also be used to provide an index of bone health from the relationship of the cortical thickness to the length and width of the bones $(64,65)$. These developments that have occurred in recent years in bone age measurements using artificial intelligence systems now allow much more objective evaluation. The models continue to be refined and validated and are providing much greater accuracy that in turn provides increased precision in assessment of adult height prediction.

\section{Prediction Models}

One of the still unresolved problems of GH treatment of a short child is how much height growth should be expected, in the short-term and long-term. Growth response has commonly been expressed as either observed height velocity (cm/year) or change in height SDS, based on normal reference data. The characteristics of height and height velocity show specific average patterns and changing degree of variance around the mean with age (66). Therefore, specifying a set figure, e.g. height SDS gain $>0.5$ during the first GH-treatment year (67), as a "normal" growth response is inadequate for children of different sex or age.

After it was recognized that the growth response to GH was correlated with several factors related to the treated children and the mode of treatment, the problem of a more complex response evaluation was approached by several groups in the early 1990s by means of growth prediction models $(68,69)$. In principle, prediction models are mathematical algorithms based on empirical observations from large cohorts of GH-treated children with specific diagnoses (70). Prediction models aim to explain as much as possible of the growth response within a set period of time, with the least possible error. This requires taking into consideration a child's characteristics, such as diagnosis, age and sex, and the chosen treatment modality (dose, injection frequency, time on treatment). The incorporation of laboratory parameters such as IGF-1 concentration, and factors such as genetic and proteomic markers (70), may also be considered, but this requires their standardization before implementation in models suitable for wider clinical use.

Data from the large KIGS (Pfizer International Growth Study) surveillance database provided the basis for development of various growth prediction models, in children at differing pubertal stages and diagnoses $(71,72)$. These models have been independently validated and are accessible through freely available software (https://igro-gh.com). GH dose is a prediction variable of relevance for the utility of these models in clinical practice, since dose is the only parameter that can be modified. Incorporating multiple pre-pubertal factors in the prediction models identified $\mathrm{GH}$ dose as the most important factor for patients with Turner syndrome or born small for gestational age. However, prediction analyses showed that in children with GH deficiency, disease severity is the most important predictor of growth during the first pre-pubertal year of treatment (73). The extent of responsiveness to $\mathrm{GH}$ observed during the first year of therapy is an indicator of the overall response.

Thus, early prediction of response to $\mathrm{GH}$ treatment of a child with growth failure potentially enables optimization and individualization of treatment in terms of efficacy and costs (70). Height velocity targets provide a simpler model to evaluate the appropriate response in children treated for the first two pre-pubertal years, by considering age, sex and diagnosis, but not the individual dose and other factors found relevant in prediction models $(66,74)$. 
The Gothenburg prediction model focused on children with idiopathic short stature or partial GH deficiency and assumed nothing about diagnosis (75). They compared a standard GH dose ( $43 \mu \mathrm{g} / \mathrm{kg} /$ day) with a dose adapted for predicted sensitivity (17-100 $\mu \mathrm{g} / \mathrm{kg} /$ day $)$ and, as expected, the variation in response was reduced by $32 \%$ with the individualized dose $(76,77)$. The Cologne model uses both baseline and three-month data for prediction of subsequent response to $\mathrm{GH}$, and includes baseline factors of IGF-1 level, deoxypyridinoline (as a marker of bone resorption) and bone age retardation, and height velocity in the first three months of treatment (78). However, as the bone resorption marker is rarely measured, the model has only been used to a limited extent. However, the Cologne model was recently shown to effectively predict first year response to GH treatment in patients with short stature homeoboxcontaining gene (SHOX) deficiency (79).

Baseline IGF-1 SDS is used in the Cologne model, whereas values both at baseline and during treatment have been used in other prediction studies in children with growth failure due to GH deficiency and other conditions $(70,80,81,82)$. These models use multivariate linear regression to identify factors associated with response for inclusion in the models. However, artificial intelligence techniques of machinelearning and neural networks have been suggested to detect both linear and non-linear variables with no pre-conceived assumptions, and may prove more flexible and useful in clinical practice (83). Initial studies suggest that early growth response and IGF-1 concentration changes were among the most important predictors of long-term response (84). Accurate prediction of growth outcomes could help in educating patients and their families and managing their expectations. While applications (apps) designed for personal use that incorporate prediction models are being developed (85), accuracy and validation are so far unknown. Very few apps currently include education and links between patients, caregivers and healthcare professionals. A better understanding of how patients can use such apps is required and there remains an unmet need for assessment of quality and physician endorsement of such tools for use in clinical practice.

\section{Interpretation of IGF-1 Data}

Determination of IGF-1 level has many uses in children with growth failure because it has a long half-life in blood and a stable circadian concentration. Therefore, single daily measurements can be taken and a consensus guideline for measurement was developed (86). Current methods for measuring total IGF-1 concentration require separation from its binding proteins using two-step acidification and neutralization, with blocking of re-aggregation by adding an excess of IGF-2 (87). Nevertheless, different commercial assays are available and their reference intervals vary, so it is important to note which assay is used when comparing data $(88,89)$. IGF-1 concentrations change with age and gender so that normative data have been determined from large numbers of healthy children and adolescents (87). This enables appropriate correction to provide SDS values, although the correct normative data should be used because diverse cohorts may give different reference measurements $(90,91)$. Such differences may give clinically relevant variation when used to establish a diagnosis of $\mathrm{GH}$ deficiency (92). Clinical background of the patient should be considered when determining whether an IGF-1 assay is necessary and how the result should be interpreted; also the test may require repeating if clinical features and laboratory results are discrepant (93). Nutritional history should also be considered in evaluation of IGF-1 when assessing GH status as both short-term and chronic under-nutrition or over-nutrition can affect circulating concentration and body mass index should be considered when interpreting IGF-1 level (94).

IGF-1 SDS is used not only to aid in identifying the cause of growth failure, but also to assess whether, and how well, a short child will benefit from GH treatment (95). In patients with GH deficiency, normalization of IGF-1 SDS is not always required for a good response, particularly in patients with severe deficiency. A greater response is generally seen in those with the lowest baseline values. Using artificial intelligence neural networks on data for patients with nonacquired isolated GH deficiency, more severely reduced IGF1 SDS at baseline was shown to be a significant indicator of GH response, both in the first year and for adult height (84). In evaluating IGF-1 level, the cause of GH deficiency should be considered, because children with acquired $\mathrm{GH}$ deficiency have higher IGF-1 SDS than those with nonacquired deficiency (96). In patients without obvious GH deficiency and who are classified as idiopathic short stature, IGF-1 SDS may be below normal for approximately $40 \%$ (87). During GH treatment, a low IGF-1 SDS may be due to low sensitivity, concomitant illness or malnutrition/ malabsorption, or poor adherence with the therapy $(96,97)$. A normalized IGF-1 SDS with low response may also suggest poor adherence, with GH correctly administered only for a few days before evaluation; better evaluation of continuous adherence may then be necessary, and addressing issues of adherence could improve response $(98,99)$. Maintaining a normalized IGF-1 SDS, without excessive values, is also required from a safety point of view $(95,100)$. While guidelines recommend a decrease in GH dose when IGF-1 
SDS is $>+2$ (101), this may not always occur in practice, particularly if response is only assessed from height velocity (102). Maintaining a set IGF-1 SDS has also been used to adjust GH dose in studies of children with GH deficiency or idiopathic short stature and was shown to enable a better growth response (103). However, non-approved high doses of GH were used in some children when IGF-1 was titrated to +2 SDS in that study, and titrating to 0 SDS was subsequently shown to achieve a better long-term height gain per dose and was potentially safer (104).

\section{Conclusion}

Digital health and computer-based technologies are rapidly altering healthcare services to make medicine much more patient-centered and personalized. While there have been great advances in use of digital tools and use of artificial intelligence, the importance of this research is only just beginning to be recognized in the field of pediatric endocrinology and growth failure. Algorithms for height monitoring can now be integrated into electronic health records, which can increase the diagnostic yield and identify individual children who may have growth failure. However, the lack of accurate centralized health records in many countries is slowing this referral and diagnosis progress. At a more individual level, various digital health tools are being developed that can provide better identification of disorders and promote effective engagement between clinicians and patients. Growth monitoring applications for phones and tablet computers are being developed, based on longitudinal growth studies. Such technologies should form part of the overall clinical management of children with growth failure.

When short stature is identified, standardizing the diagnoses associated with pediatric endocrinology requires a comprehensive classification system, in which the organization of diagnoses is well defined in order to prevent misclassification. Computerization of health records enables transformation of identified medical conditions into code numbers, which can then be used by multiple organizations to analyze population data on health and healthcare. Most systems currently in use are either complicated or diagnoses are insufficiently defined and, therefore, do not fit the needs of the scientific, governmental and healthcare communities. ICPED is an online classification system that is simple, comprehensive and fulfills the needs of such users, can be standardized worldwide and incorporated into hospital registries. This would allow wider access and better use of electronic health records.

Assessment of the cause of growth failure in a child frequently includes cranial imaging and new techniques are being devised. A recent development is the routine inclusion of T2-DRIVE into sellar MRI protocols. In light of recent safety concerns regarding gadolinium contrast agents, the computer-aided technique is considered a valid alternative for pituitary imaging without gadolinium in patients with pituitary hormone deficiencies. T2-DRIVE is advocated for more accurate diagnosis of pituitary gland abnormalities since it has been shown to provide better contrast than gadolinium agents. However, it should always be noted that knowledge of the normal pituitary dimensions is required for interpretation of any technique and good clinical expertise remains vital for accurate diagnosis.

New computerized techniques for measurement of bone age are using machine-learning to become much more accurate and precise. As these are objective, rather than previous subjective manual ratings, they are much less variable, can be used for both short and tall children, and are adaptable to various ethnicities. The BoneXpert system, which uses machine-learning though not deep-learning, is the only medically certified and systematically validated technique. As well as providing rapid and accurate bone age measurements and adult height predictions, it also provides a bone health index that can be used for multiple medical conditions. However, automated techniques such as BoneXpert, should continually be compared with manual ratings in order that clinicians do not become totally dependent on them. The techniques are still developing, with mistakes occasionally occurring, and at present syndromes and anomalies cannot be automatically detected. Therefore, clinical experience and judgment is still required.

A variety of models to predict the response to $\mathrm{GH}$ treatment in individual children with growth failure have been developed and validated over time. However, they are still largely underused in assessment of growth potential. Various factors are included in different models, such as patient characteristics and treatment modalities, but incorporating further laboratory, proteomic and genetic predictors could potentially improve accuracy. Until recently, the models relied on multivariate regression analysis. However, newer methods are beginning to be developed that use deep-neural networks and machine-learning techniques, which can analyze non-linear as well as linear relationships and do not require a priori assumptions about importance of various factors. Prediction models are now also being incorporated into apps, to educate and help patients understand their condition. However, these require clarity in the models being used, expert validation and assessment by endocrinologists.

Some prediction models use IGF-1 SDS as a factor and IGF-1 SDS may also be used to evaluate response to GH treatment for short stature. Machine-learning techniques indicated that 
baseline IGF-1 SDS is among the most important indicators of response to GH treatment. However, IGF-1 measurements should be considered with care because results can vary widely between different assays. Laboratories should ensure that appropriate normative data are used to determine SDS values, and pubertal stage of the child should be taken into consideration in addition to age, gender and nutritional history, when interpreting results. As there is imprecision in assays, borderline values for use in clinical diagnosis of short stature should be repeated using a second blood sample and clinical history assessed when evaluating IGF-1 level. Titrating GH dose to IGF-1 helps to take into account the sensitivity of treatment due to diagnostic factors and has been reported to provide better clinical outcomes.

Thus, rapid advances in computing and artificial intelligence technologies are providing many new tools for pediatric endocrinologists. Such tools are improving identification of short stature and enabling better diagnosis of causes of growth failure. Cranial imaging is becoming more accurate and sensitive, bone age and bone health can be evaluated more objectively, prediction of response to $\mathrm{GH}$ treatment is improving and use of IGF-1 measurement is becoming more consistent. However, this research has only really scratched the surface and development of new computerlearning techniques could be further explored in terms of digitalization and development of patients-centric solutions. New eHealth tools can help pediatric endocrinologists by making their clinical assessment and patient management more efficient. Most tools are currently designed to be used by clinicians, although future directions may need to explore new ways in which patients can access the technologies more directly. While clinicians need to keep abreast of all these new techniques, clinical decisions should always be based on their experience. However, these new digital technologies should provide better communications between clinicians and patients. Treatment decisions based on these new techniques should always be patient-centered, in order to personalize and optimize assessment of child growth and management of growth failure.

\section{Acknowledgments}

Medical writing assistance was provided by Dr. Peter Bates, Cambridge Medical Writing Services, UK, funded by Merck KGaA, Darmstadt, Germany.

\section{Ethics}

Peer-review: Internally peer-reviewed.

\section{Authorship Contributions}

All authors were involved in the critical revision of the current work for important intellectual content, and gave final approval of the version of the manuscript to be published. All authors have agreed to be accountable for all aspects of the work in ensuring that questions related to the accuracy or integrity of any part of it are appropriately investigated and resolved.

Concept/Design: José I. Labarta, Michael B. Ranke, Mohamad Maghnie, David Martin, Laura Guazzarotti, Roland Pfäffle, Ekaterina Koledova, Jan M. Wit, Data Collection or Processing: José I. Labarta, Michael B. Ranke, Mohamad Maghnie, David Martin, Laura Guazzarotti, Roland Pfäffle, Ekaterina Koledova, Jan M. Wit, Analysis or Interpretation and Literature Search: José I. Labarta, Michael B. Ranke, Mohamad Maghnie, David Martin, Laura Guazzarotti, Roland Pfäffle, Ekaterina Koledova, Jan M. Wit, Writing: José I. Labarta, Michael B. Ranke, Mohamad Maghnie, David Martin, Laura Guazzarotti, Roland Pfäffle, Ekaterina Koledova, Jan M. Wit.

Conflict of interest: J.I.L., M.R., D.M., and L.G. report no conflicts of interest. M.M. has received speaker's fees from Merck, Sandoz, Pfizer and Novo Nordisk, and served on advisory boards of Merck, Sandoz, Pfizer, Novo Nordisk and Ascendis. R.P. has received speaker's fees from Merck, Sandoz and Novo Nordisk, and served on advisory boards for Sandoz and Novo Nordisk. J.M.W. has served as consultant to Merck KGaA, Agios, Aeterna Zentaris and Ammonett, and received speaker's fees from Pfizer, Versartis, Sandoz, Lilly, Merck, JCR, Ipsen and Novo Nordisk. E.K. is an employee of Merck KGaA, Darmstadt, Germany.

Financial Disclosure: The third $360^{\circ}$ European Meeting on Growth and Endocrine Disorders was funded by Merck KGaA, Germany. No payment has been offered or will be offered to the authors for authoring this publication and no compensation will be provided for the time they spend on the publication development.

\section{References}

1. Teran E, Chesner J, Rapaport R. Growth and growth hormone: an overview. Growth Horm IGF Res 2016;28:3-5. Epub 2016 Feb 23

2. Maghnie M, Labarta JI, Koledova E, Rohrer TR. Short stature diagnosis and referral. Front Endocrinol (Lausanne) 2018;8:374.

3. Wit JM, Kamp GA, Oostdijk W; on behalf of the Dutch Working Group on Triage and Diagnosis of Growth Disorders in Children. Towards a Rational and Efficient Diagnostic Approach in Children Referred for Growth Failure to the General Paediatrician. Horm Res Paediatr 2019;91:223-240. Epub 2019 Jun 13

4. Collett-Solberg PF, Ambler G, Backeljauw PF, Bidlingmaier M, Biller BMK, Boguszewski MCS, Cheung PT, Choong CSY, Cohen LE, Cohen P, Dauber A, Deal CL, Gong C, Hasegawa Y, Hoffman AR, Hofman PL, Horikawa R, Jorge AAL, Juul A, Kamenický P, Khadilkar V, Kopchick JJ, Kriström B, Lopes MLA, Luo X, Miller BS, Misra M, Netchine I, Radovick S, Ranke MB, Rogol AD, Rosenfeld RG, Saenger P, Wit JM, Woelfle J. Diagnosis, Genetics, and Therapy of Short Stature in Children: A 
Growth Hormone Research Society International Perspective. Horm Res Paediatr 2019;92:1-14. Epub 2019 Sep 12

5. Argente J, Tatton-Brown K, Lehwalder D, Pfäffle R. Genetics of growth disorders-which patients require genetic testing? Front Endocrinol (Lausanne) 2019;10:602.

6. Inzaghi E, Reiter E, Cianfarani S. The challenge of defining and investigating the causes of idiopathic short stature and finding an effective therapy. Horm Res Paediatr 2019;92:71-83. Epub 2019 Oct 2

7. Wit JM, Deeb A, Bin-Abbas B, Al Mutair A, Koledova E, Savage MO. Achieving optimal short- and long-term responses to paediatric growth hormone therapy. J Clin Res Pediatr Endocrinol 2019;11:329340. Epub 2019 Jul 9

8. Sävendahl L, Polak M, Backeljauw P, Blair J, Miller BS, Rohrer TR, Pietropoli A, Ostrow V, Ross J. Treatment of Children With GH in the United States and Europe: Long-Term Follow-Up From NordiNet ${ }^{\circledR}$ IOS and ANSWER Program. J Clin Endocrinol Metab 2019;104:4730-4742.

9. Richmond E, Rogol AD. Current indications for growth hormone therapy for children and adolescents. Endocr Dev 2010;18;92-108. Epub 2010 Jun 3

10. Navarro R, Dunn JD, Lee PA, Owens GM, Rapaport R. Translating clinical guidelines into practice: the effective and appropriate use of human growth hormone. Am J Manag Care 2013;19(15 Suppl):281-289.

11. Grimberg A, DiVall SA, Polychronakos C, Allen DB, Cohen LE, Quintos JB, Rossi WC, Feudtner C, Murad MH; Drug and Therapeutics Committee and Ethics Committee of the Pediatric Endocrine Society. Guidelines for Growth Hormone and Insulin-Like Growth Factor-I Treatment in Children and Adolescents: Growth Hormone Deficiency, Idiopathic Short Stature, and Primary Insulin-Like Growth Factor-I Deficiency. Horm Res Paediatr 2016;86:361-397. Epub 2016 Nov 25

12. Grote FK, Oostdijk W, De Muinck Keizer-Schrama SM, van Dommelen P, van Buuren S, Dekker FW, Ketel AG, Moll HA, Wit JM. The diagnostic work up of growth failure in secondary health care; an evaluation of consensus guidelines. BMC Pediatr 2008;8:21

13. Savage MO, Backeljauw PF, Calzada R, Cianfarani S, Dunkel L, Koledova E, Wit JM, Yoo HW. Early detection, referral, investigation, and diagnosis of children with growth disorders. Horm Res Paediatr 2016;85:325-332. Epub 2016 Apr 8

14. Stalman SE, Hellinga I, van Dommelen P, Hennekam RC, Saari A, Sankilampi U, Dunkel L, Wit JM, Kamp GA, Plötz FB. Application of the Dutch, Finnish and British Screening Guidelines in a Cohort of Children with Growth Failure. Horm Res Paediatr 2015;84:376-382. Epub 2015 Oct 9

15. Grote FK, Oostdijk W, De Muinck Keizer-Schrama SM, Dekker FW, van Dommelen P, van Buuren S, Lodder-van der Kooij AM, Verkerk $\mathrm{PH}$, Wit JM. Referral patterns of children with poor growth in primary health care. BMC Public Health 2007;7:77.

16. Saari A, Sankilampi U, Dunkel L. Multiethnic WHO growth charts may not be optimal in the screening of disorders affecting height: Turner syndrome as a model. JAMA Pediatr 2013;167:194-195.

17. Christesen HT, Pedersen BT, Pournara E, Petit IO, Júlíusson PB. Short Stature: Comparison of WHO and National Growth Standards/ References for Height. PLoS One 2016;11:e0157277.

18. Scherdel P, Hjelm N, Salaün JF; EBGM IV study group, Heude B, Chalumeau M. Survey highlights important discrepancies between definitions of paediatric abnormal growth taught to medical students in 23 European countries. Acta Paediatr 2018;107:1218-1222. Epub 2018 Mar 5

19. Scherdel P, Dunkel L, van Dommelen P, Goulet O, Salaün JF, Brauner R, Heude B, Chalumeau M. Growth monitoring as an early detection tool: a systematic review. Lancet Diabetes Endocrinol 2016;4:447456. Epub 2016 Jan 15

20. Gascoin-Lachambre G, Brauner R, Duche L, Chalumeau M. Pituitary stalk interruption syndrome: diagnostic delay and sensitivity of the auxological criteria of the Growth Hormone Research Society. PLoS One $2011 ; 6:$ e16367.

21. Saari A, Sankilampi U, Hannila ML, Saha MT, Mäkitie O, Dunkel L. Screening of turner syndrome with novel auxological criteria facilitates early diagnosis. J Clin Endocrinol Metab 2012;97:2125-2132. Epub $2012 \operatorname{Sep} 4$

22. Scherdel P, Matczak S, Léger J, Martinez-Vinson C, Goulet O, Brauner R, Nicklaus S, Resche-Rigon M, Chalumeau M, Heude B. Algorithms to Define Abnormal Growth in Children: External Validation and HeadTo-Head Comparison. J Clin Endocrinol Metab 2019;104:241-249.

23. Grote FK, van Dommelen P, Oostdijk W, de Muinck Keizer-Schrama SM, Verkerk PH, Wit JM, van Buuren S. Developing evidence-based guidelines for referral for short stature. Arch Dis Child 2008;93:212217. Epub 2007 Oct 1

24. Sankilampi U, Saari A, Laine T, Miettinen PJ, Dunkel L. Use of electronic health records for automated screening of growth disorders in primary care. JAMA 2013;310:1071-1072.

25. Carsley S, Pope EI, Anderson LN, Tremblay MS, Tu K, Birken CS; Team to Address Bariatric Care in Canadian Children. Temporal trends in severe obesity prevalence in children and youth from primary care electronic medical records in Ontario: a repeated cross-sectional study. CMAJ Open 2019;7:351-359

26. Wray CV, Brauer PM, Heuberger RA, Logomarsino JV. Improving documentation of pediatric height, weight, and body mass index by primary care providers. Can J Diet Pract Res 2018;79:186-190. Epub 2018 Jul 16

27. Wit JM, Ranke MB, Kelnar CJ. ESPE classification of paediatric endocrine disorders. Horm Res Paediatr 2007;68(Suppl 2):1-9.

28. Quigley CA, Ranke MB. International classification of pediatric endocrine diagnoses (ICPED). 2015. Last accessed date: May 2020. Available from: http://www.icped.org

29. Wit JM. International classification of pediatric endocrine diagnoses. Horm Res Paediatr 2016;86:212-214. Epub 2016 Sep 3

30. Growth Hormone Research Society. Consensus guidelines for the diagnosis and treatment of growth hormone (GH) deficiency in childhood and adolescence: summary statement of the GH Research Society. J Clin Endocrinol Metab 2000;85:3990-3993.

31. Secco A, Allegri AE, di lorgi N, Napoli F, Calcagno A, Bertelli E, Olivieri I, Pala G, Parodi S, Gastaldi R, Rossi A, Maghnie M. Posterior pituitary (PP) evaluation in patients with anterior pituitary defect associated with ectopic PP and septo-optic dysplasia. Eur J Endocrinol 2011;165:411-420. Epub 2011 Jul 12

32. Di Iorgi N, Morana G, Maghnie M. Pituitary stalk thickening on MRI: when is the best time to re-scan and how long should we continue rescanning for? Clin Endocrinol (Oxf) 2015;83:449-455. Epub 2015 Apr 6

33. Severino M, Allegri AE, Pistorio A, Roviglione B, Di Iorgi N, Maghnie M, Rossi A. Midbrain-hindbrain involvement in septo-optic dysplasia. AJNR Am J Neuroradiol 2014;35:1586-1592. Epub 2014 Apr 24

34. Di Iorgi N, Morana G, Allegri AE, Napoli F, Gastaldi R, Calcagno A, Patti G, Loche S, Maghnie M. Classical and non-classical causes of GH deficiency in the paediatric age. Best Pract Res Clin Endocrinol Metab 2016;30:705-736. Epub 2016 Nov 24

35. Maghnie M, Lindberg A, Koltowska-Häggström M, Ranke MB. Magnetic resonance imaging of CNS in 15,043 children with GH deficiency in KIGS (Pfizer International Growth Database). Eur J Endocrinol 2013;168:211-217. 
36. di Iorgi N, Secco A, Napoli F, Tinelli C, Calcagno A, Fratangeli N, Ambrosini L, Rossi A, Lorini R, Maghnie M. Deterioration of growth hormone $(\mathrm{GH})$ response and anterior pituitary function in young adults with childhood-onset GH deficiency and ectopic posterior pituitary: a two-year prospective follow-up study. J Clin Endocrinol Metab 2007;92:3875-3884. Epub 2007 Jul 31

37. Maghnie M, Strigazzi C, Tinelli C, Autelli M, Cisternino M, Loche $\mathrm{S}$, Severi F. Growth hormone (GH) deficiency (GHD) of childhood onset: reassessment of $\mathrm{GH}$ status and evaluation of the predictive criteria for permanent GHD in young adults. J Clin Endocrinol Metab 1999;84:1324-1328.

38. Gutierrez JE, Rosenberg M, Seemann J, Breuer J, Haverstock D, Agris J, Balzer T, Anzalone N. Safety and Efficacy of Gadobutrol for Contrastenhanced Magnetic Resonance Imaging of the Central Nervous System: Results from a Multicenter, Double-blind, Randomized, Comparator Study. Magn Reson Insights 2015;8:1-10.

39. Tanaka A, Masumoto T, Yamada H, Kurauchi M, Breuer J. A Japanese, multicenter, open-label, phase 3 study to investigate the safety and efficacy of gadobutrol for contrast-enhanced MR imaging of the central nervous system. Magn Reson Med Sci 2016;15:227-236. Epub 2015 Dec 21

40. Gale EM, Caravan P, Rao AG, McDonald RJ, Winfeld M, Fleck RJ, Gee MS. Gadolinium-based contrast agents in pediatric magnetic resonance imaging. Pediatr Radiol 2017;47:507-521. Epub 2017 Apr 13

41. Olchowy C, Cebulski K, Łasecki M, Chaber R, Olchowy A, Kałwak $\mathrm{K}$, Zaleska-Dorobisz $U$. The presence of the gadolinium-based contrast agent depositions in the brain and symptoms of gadolinium neurotoxicity - A systematic review. PLoS One 2017;12:e0171704.

42. U.S. Food \& Drug Administration. FDA warns that gadolinium-based contrast agents (GBCAs) are retained in the body; requires new class warnings. Silver Spring (MD): U.S. Food and Drug Administration (FDA). 2018. Last accessed date: May 2020. Available from: https:// www.fda.gov/drugs/drugsafety/ucm589213.htm

43. European Medicines Agency. Gadolinium-containing contrast agents. London 2017. Last accessed date: May 2020. Available from: https:// www.ema.europa.eu/en/medicines/human/referrals/gadoliniumcontaining-contrast-agents

44. Godano E, Morana G, Di Iorgi N, Pistorio A, Allegri AEM, Napoli F, Gastaldi R, Calcagno A, Patti G, Gallizia A, Notarnicola S, Giaccardi M, Noli S, Severino M, Tortora D, Rossi A, Maghnie M. Role of MRI T2-DRIVE in the assessment of pituitary stalk abnormalities without gadolinium in pituitary diseases. Eur J Endocrinol 2018;178:613-622.

45. Thodberg HH, Jenni OG, Caflisch J, Ranke MB, Martin DD. Prediction of adult height based on automated determination of bone age. J Clin Endocrinol Metab 2009;94:4868-4874. Epub 2009 Nov 19

46. Martin DD, Wit JM, Hochberg Z, Sävendahl L, van Rijn RR, Fricke O, Cameron N, Caliebe J, Hertel T, Kiepe D, Albertsson-Wikland K, Thodberg HH, Binder G, Ranke MB. The use of bone age in clinical practice - part 1. Horm Res Paediatr 2011;76:1-9. Epub 2011 Jun 21

47. Roemmich JN, Blizzard RM, Peddada SD, Malina RM, Roche AF, Tanner JM, Rogol AD. Longitudinal assessment of hormonal and physical alterations during normal puberty in boys. IV: Predictions of adult height by the Bayley-Pinneau, Roche-Wainer-Thissen, and Tanner-Whitehouse methods compared. Am J Hum Biol 1997;9:371380.

48. Tanner JM, Oshman D, Lindgren G, Grunbaum JA, Elsouki R, Labarthe D. Reliability and validity of computer-assisted estimates of TannerWhitehouse skeletal maturity (CASAS): comparison with the manual method. Horm Res 1994;42:288-294.
49. Schwarze CP, Arens D, Haber HP, Wollmann HA, Binder G, Mayer EI, Ranke MB. Bone age in 116 untreated patients with Turner's syndrome rated by a computer-assisted method (CASAS). Acta Paediatr 1998;87:1146-1150.

50. Thodberg HH, Kreiborg S, Juul A, Pedersen KD. The BoneXpert method for automated determination of skeletal maturity. IEEE Trans Med Imaging 2009;28:52-66.

51. Martin DD, Deusch D, Schweizer R, Binder G, Thodberg HH, Ranke MB. Clinical application of automated Greulich-Pyle bone age determination in children with short stature. Pediatr Radiol 2009;39:598-607. Epub 2009 Mar 31

52. Thodberg HH, Martin DD. Validation of a new version of BoneXpert bone age in children with congenital adrenal hyperplasia (CAH), precocious puberty (PP), growth hormone deficiency (GHD), Turner syndrome (TS), and other short stature diagnoses. Horm Res Paediatr 2019;91 (Suppl 1):26.

53. Lee H, Tajmir S, Lee J, Zissen M, Yeshiwas BA, Alkasab TK, Choy G, Do S. Fully automated deep learning system for bone age assessment. J Digit Imaging 2017;30:427-441

54. Kim JR, Shim WH, Yoon HM, Hong SH, Lee JS, Cho YA, Kim S. Computerized Bone Age Estimation Using Deep Learning Based Program: Evaluation of the Accuracy and Efficiency. AJR Am J Roentgenol 2017;209:1374-1380. Epub 2017 Sep 12

55. Erickson BJ, Korfiatis P, Akkus Z, Kline TL. Machine learning for medical imaging. Radiographics 2017;37:505-515. Epub 2017 Feb 17

56. Bui TD, Lee JJ, Shin J. Incorporated region detection and classification using deep convolutional networks for bone age assessment. Artif Intell Med 2019;97:1-8. Epub 2019 Apr 30

57. Liu Y, Zhang C, Cheng J, Chen X, Wang ZJ. A multi-scale data fusion framework for bone age assessment with convolutional neural networks. Comput Biol Med 2019;108:161-173. Epub 2019 Mar 19

58. Larson DB, Chen MC, Lungren MP, Halabi SS, Stence NV, Langlotz CP. Performance of a deep-learning neural network model in assessing skeletal maturity on pediatric hand radiographs. Radiology 2018;287:313-322. Epub 2017 Nov 2

59. Halabi SS, Prevedello LM, Kalpathy-Cramer J, Mamonov AB, Bilbily A, Cicero M, Pan I, Pereira LA, Sousa RT, Abdala N, Kitamura FC, Thodberg $\mathrm{HH}$, Chen L, Shih G, Andriole K, Kohli MD, Erickson BJ, Flanders AE. The RSNA Pediatric Bone Age Machine Learning Challenge. Radiology 2019;290:498-503. Epub 2018 Nov 27

60. Siegel EL. What can we learn from the RSNA pediatric bone age machine learning challenge? Radiology 2019;290:504-505. Epub 2018 Dec 4

61. Thodberg HH, van Rijn RR, Jenni OG, Martin DD. Automated determination of bone age from hand X-rays at the end of puberty and its applicability for age estimation. Int J Legal Med 2017;131:771780. Epub 2016 Oct 18

62. Artioli TO, Alvares MA, Carvalho Macedo VS, Silva TS, Avritchir R, Kochi C, Longui CA. Bone age determination in eutrophic, overweight and obese Brazilian children and adolescents: a comparison between computerized BoneXpert and Greulich-Pyle methods. Pediatr Radiol 2019;49:1185-1191. Epub 2019 May 31

63. Martin DD, Schittenhelm J, Thodberg HH. Validation of adult height prediction based on automated bone age determination in the Paris Longitudinal Study of healthy children. Pediatr Radiol 2016;46:263269 .

64. Twilt M, Pradsgaard D, Spannow AH, Horlyck A, Heuck C, Herlin T Joint cartilage thickness and automated determination of bone age and bone health in juvenile idiopathic arthritis. Pediatr Rheumatol Online J 2017;15:63. 
65. Schündeln MM, Marschke L, Bauer JJ, Hauffa PK, Schweiger B, FührerSakel D, Lahner H, Poeppel TD, Kiewert C, Hauffa BP, Grasemann C. A Piece of the Puzzle: The Bone Health Index of the BoneXpert Software Reflects Cortical Bone Mineral Density in Pediatric and Adolescent Patients. PLoS One 2016;11:e0151936.

66. Bakker B, Frane J, Anhalt H, Lippe B, Rosenfeld RG. Height velocity targets from the national cooperative growth study for first-year growth hormone responses in short children. J Clin Endocrinol Metab 2008;93;352-357. Epub 2007 Nov 13

67. Bang P, Bjerknes R, Dahlgren J, Dunkel L, Gustafsson J, Juul A, Kriström B, Tapanainen P, Aberg V. A comparison of different definitions of growth response in short prepubertal children treated with growth hormone. Horm Res Paediatr 2011;75:335-345. Epub 2011 Jan 12

68. Ranke MB, Guilbaud O, Lindberg A, Cole T. Prediction of the growth response in children with various growth disorders treated with growth hormone: analyses of data from the Kabi Pharmacia International Growth Study. International Board of the Kabi Pharmacia International Growth Study. Acta Paediatr Suppl 1993;82(Suppl 391):82-89.

69. Ranke MB, Lindberg A, Chatelain P, Wilton P, Cutfield W, AlbertssonWikland K, Price DA. Derivation and validation of a mathematical model for predicting the response to exogenous recombinant human growth hormone $(\mathrm{GH})$ in prepubertal children with idiopathic $\mathrm{GH}$ deficiency. KIGS International Board. Kabi Pharmacia International Growth Study. J Clin Endocrinol Metab 1999;84:1174-1183.

70. Wit JM, Ranke MB, Albertsson-Wikland K, Carrascosa A, Rosenfeld RG, Van Buuren S, Kristrom B, Schoenau E, Audi L, Hokken-Koelega AC, Bang P, Jung H, Blum WF, Silverman LA, Cohen P, Cianfarani S, Deal C, Clayton PE, de Graaff L, Dahlgren J, Kleintjens J, Roelants M. Personalized approach to growth hormone treatment: clinical use of growth prediction models. Horm Res Paediatr 2013;79:257-270. Epub 2013 May 28

71. Ranke MB, Lindberg A. Predicting growth in response to growth hormone treatment. Growth Horm IGF Res 2009;19:1-11. Epub 2008 Sep 27

72. Ranke MB, Lindberg A, Mullis PE, Geffner ME, Tanaka T, Cutfield WS, Tauber M, Dunger D. Towards optimal treatment with growth hormone in short children and adolescents: evidence and theses. Horm Res Paediatr 2013;79:51-67. Epub 2013 Feb 26

73. Loftus J, Lindberg A, Aydin F, Gomez R, Maghnie M, Rooman R, Steinkamp H, Doerr H, Ranke M, Camacho-Hubner C. Individualised growth response optimisation (iGRO) tool: an accessible and easy-touse growth prediction system to enable treatment optimisation for children treated with growth hormone. J Pediatr Endocrinol Metab 2017;30;1019-1026.

74. Ranke MB, Lindberg A; KIGS International Board. Observed and predicted growth responses in prepubertal children with growth disorders: guidance of growth hormone treatment by empirical variables. J Clin Endocrinol Metab 2010;95:1229-1237. Epub 2010 Jan 22

75. Wikland KA, Kriström B, Rosberg S, Svensson B, Nierop AF. Validated multivariate models predicting the growth response to $\mathrm{GH}$ treatment in individual short children with a broad range in GH secretion capacities. Pediatr Res 2000;48:475-484

76. Kriström B, Wikland KA. Growth prediction models, concept and use. Horm Res 2002;57(Suppl 2):66-70.

77. Kriström B, Aronson AS, Dahlgren J, Gustafsson J, Halldin M, Ivarsson SA, Nilsson NO, Svensson J, Tuvemo T, Albertsson-Wikland K. Growth hormone $(\mathrm{GH})$ dosing during catch-up growth guided by individual responsiveness decreases growth response variability in prepubertal children with GH deficiency or idiopathic short stature. J Clin Endocrinol Metab 2009;94:483-490. Epub 2008 Nov 11
78. Schönau E, Westermann F, Rauch F, Stabrey A, Wassmer G, Keller E, Brämswig J, Blum WF; German Lilly Growth Response Study Group. A new and accurate prediction model for growth response to growth hormone treatment in children with growth hormone deficiency. Eur J Endocrinol 2001;144:13-20.

79. Hoyer-Kuhn H, Franklin J, Jones C, Blum WF, Schoenau E. Growth response to growth hormone treatment in patients with SHOX deficiency can be predicted by the Cologne prediction model. J Pediatr Endocrinol Metab 2018;31:25-31.

80. Dahlgren J, Kriström B, Niklasson A, Nierop AF, Rosberg S, AlbertssonWikland K. Models predicting the growth response to growth hormone treatment in short children independent of $\mathrm{GH}$ status, birth size and gestational age. BMC Med Inform Decis Mak 2007;7:40.

81. Davenport ML, Crowe BJ, Travers SH, Rubin K, Ross JL, Fechner PY, Gunther DF, Liu C, Geffner ME, Thrailkill K, Huseman C, Zagar AJ, Quigley CA. Growth hormone treatment of early growth failure in toddlers with Turner syndrome: a randomized, controlled, multicenter trial. J Clin Endocrinol Metab 2007;92:3406-3416. Epub 2007 Jun 26

82. Lee PA, Germak J, Gut R, Khutoryansky N, Ross J. Identification of factors associated with good response to growth hormone therapy in children with short stature: results from the ANSWER Program ${ }^{\circledR}$. Int J Pediatr Endocrinol 2011;2011:6

83. Smyczynska J, Hilczer M, Smyczynska U, Stawerska R, Tadeusiewicz R, Lewinski A. Neural network models - a novel tool for predicting the efficacy of growth hormone $(\mathrm{GH})$ therapy in children with short stature. Neuro Endocrinol Lett 2015;36:348-353.

84. Smyczyńska U, Smyczyńska J, Hilczer M, Stawerska R, Tadeusiewicz $\mathrm{R}$, Lewiński A. Pre-treatment growth and IGF-I deficiency as main predictors of response to growth hormone therapy in neural models. Endocr Connect 2018;7:239-249. Epub 2017 Dec 14

85. Fernandez-Luque L, Labarta JI, Palmer E, Koledova E. Content analysis of apps for growth monitoring and growth hormone treatment: systematic search in the android app store. JMIR Mhealth Uhealth 2020;8:e16208.

86. Clemmons DR. Consensus statement on the standardization and evaluation of growth hormone and insulin-like growth factor assays. Clin Chem 2011;57:555-559. Epub 2011 Feb 1

87. Blum WF, Böttcher C, Wudy SA. Insulin-like growth factors and their binding proteins. In: Ranke MB, Mullis PE (eds). Diagnostics of Endocrine Function in Children and Adolescents. Basel, Karger, 2011;4157-4182.

88. Chanson P, Arnoux A, Mavromati M, Brailly-Tabard S, Massart C, Young J, Piketty ML, Souberbielle JC; VARIETE Investigators. Reference values for IGF-I serum concentrations: comparison of six immunoassays. J Clin Endocrinol Metab 2016;101:3450-3458. Epub 2016 May 11

89. Aneke-Nash CS, Dominguez-Islas C, Bůžková P, Qi Q, Xue X, Pollak M, Strickler HD, Kaplan RC. Agreement between circulating IGF-I, IGFBP-1 and IGFBP-3 levels measured by current assays versus unavailable assays previously used in epidemiological studies. Growth Horm IGF Res 2016;26:11-16. Epub 2015 Dec 8

90. Broeren MAC, Krabbe JG, Boesten LS, Hokken-Koelega ACS, de Rijke YB. Impact of the choice of IGF-I assay and normative dataset on the diagnosis and treatment of growth hormone deficiency in children. Horm Res Paediatr 2018;90:181-189. Epub 2018 Oct 4

91. Bedogni G, Giannone G, Maghnie M, Giacomozzi C, Di Iorgi N, Pedicelli S, Peschiaroli E, Melioli G, Muraca M, Cappa M, Cianfarani S. Serum insulin-like growth factor-I (IGF-I) reference ranges for chemiluminescence assay in childhood and adolescence. Data from a population of in- and out-patients. Growth Horm IGF Res 2012;22:134138. Epub 2012 May 14 
92. Mavromati M, Kuhn E, Agostini H, Brailly-Tabard S, Massart C, Piketty ML, Arnoux A, Young J, Souberbielle JC, Chanson P. Classification of patients with GH disorders may vary according to the IGF-I assay. J Clin Endocrinol Metab 2017;102:2844-2852.

93. Wit JM, Bidlingmaier M, de Bruin C, Oostdijk W. A proposal for the interpretation of the serum IGF-I concentration as part of laboratory screening in children with growth failure. J Clin Res Pediatr Endocrinol 2020;12:130-139. Epub 2019 Dec 17

94. Hawkes CP, Grimberg A. Measuring growth hormone and insulin-like growth factor-I in infants: what is normal? Pediatr Endocrinol Rev 2013;11:126-146.

95. Blum WF, Alherbish A, Alsagheir A, El Awwa A, Kaplan W, Koledova E, Savage MO. The growth hormone-insulin-like growth factor-I axis in the diagnosis and treatment of growth disorders. Endocr Connect 2018;7:212-222. Epub 2018 May 3

96. Léger J, Mohamed D, Dos Santos S, Ben Azoun M, Zénaty D, Simon D, Paulsen A, Martinerie L, Chevenne D, Alberti C, Carel JC, GuilminCrepon S. Impact of the underlying etiology of growth hormone deficiency on serum IGF-I SDS levels during GH treatment in children. Eur J Endocrinol 2017;177:267-276.

97. Acerini $\mathrm{CL}$, Wac K, Bang P, Lehwalder D. Optimizing patient management and adherence for children receiving growth hormone. Front Endocrinol (Lausanne) 2017;8:313.

98. van Dommelen P, Koledova E, Wit JM. Effect of adherence to growth hormone treatment on 0-2 year catch-up growth in children with growth hormone deficiency. PLoS One 2018;13:e0206009.
99. Koledova E, Stoyanov G, Ovbude L, Davies PSW. Adherence and long-term growth outcomes: results from the easypod ${ }^{\mathrm{TM}}$ connect observational study (ECOS) in paediatric patients with growth disorders. Endocr Connect 2018;7:914-923. Epub 2018 Jul 5

100. Cianfarani S. Risk of cancer in patients treated with recombinant human growth hormone in childhood. Ann Pediatr Endocrinol Metab 2019;24:92-98

101. Wilson TA, Rose SR, Cohen P, Rogol AD, Backeljauw P, Brown R, Hardin DS, Kemp SF, Lawson M, Radovick S, Rosenthal SM, Silverman L, Speiser P; Lawson Wilkins Pediatric Endocrinology Society Drug and Therapeutics Committee. Update of guidelines for the use of growth hormone in children: the Lawson Wilkins Pediatric Endocrinology Society Drug and Therapeutics Committee. J Pediatr 2003;143:415421.

102. Oberle M, Grimberg A, Bamba V. Treatment of pre-pubertal patients with growth hormone deficiency: patterns in growth hormone dosage and insulin-like growth factor-I Z-scores. J Clin Res Pediatr Endocrinol 2017;9:208-215. Epub 2017 Feb 2

103. Cohen P, Rogol AD, Weng W, Kappelgaard AM, Rosenfeld RG, Germak J; American Norditropin Study Group. Efficacy of IGF-based growth hormone $(\mathrm{GH})$ dosing in nonGH-deficient (nonGHD) short stature children with low IGF-I is not related to basal IGF-I levels. Clin Endocrinol (Oxf) 2013;78:405-414.

104. Cohen P, Weng W, Rogol AD, Rosenfeld RG, Kappelgaard AM, Germak J. Dose-sparing and safety-enhancing effects of an IGF-I-based dosing regimen in short children treated with growth hormone in a 2-year randomized controlled trial: therapeutic and pharmacoeconomic considerations. Clin Endocrinol (Oxf) 2014;81:71-76. Epub 2014 Feb 7 